\title{
When Do Adolescents Accept or Defy to Maternal Prohibitions? The Role of Social Domain and Communication Style
}

Stijn Van Petegem ${ }^{1}$, Maarten Vansteenkiste ${ }^{2}$, Bart Soenens ${ }^{2}$, Grégoire Zimmermann ${ }^{1}$, JeanPhilippe Antonietti ${ }^{1}$, Sophie Baudat ${ }^{1}, \&$ Elien Audenaert ${ }^{2}$

${ }^{1}$ Family and Development Research Center (FADO), Institute of Psychology, University of Lausanne, Switzerland

${ }^{2}$ Department of Developmental, Personality and Social Psychology, Ghent University, Belgium

This article may not exactly replicate the final version published in the journal. The final version is published in Journal of Youth and Adolescence.

The exact reference is: Van Petegem, S., Vansteenkiste, M., Soenens, B., Zimmermann, G., Antonietti, J.-P., Baudat, S., \& Audenaert, E. (2017). When do adolescents accept or defy to maternal prohibitions? The role of social domain and communication style. Journal of Youth and Adolescence, 46, 1022-1037. 


\begin{abstract}
Drawing upon both Social-Cognitive Domain Theory and Self-Determination Theory, the goal of the present multi-informant study was to test whether the correlates of maternal prohibitions depend on what is prohibited (i.e., the content of the social domain involved), thereby contrasting moral with friendship prohibitions, as well on how the prohibition is communicated, thereby contrasting an autonomy-supportive with a controlling communication style. In a sample of adolescents $(N=196$; mean age $=13.9$ years; $63 \%$ female $)$ and their mothers $(N=185$; mean age $=44$ years $)$, we first examined mean-level differences between the two domains in terms of mothers' degree and style of prohibition, as well as on a number of developmental outcomes (i.e., adolescents' legitimacy perceptions, internalization, and oppositional defiance). Both adolescents and mothers reported more maternal involvement in the moral domain (e.g., higher scores for degree of prohibition and controlling communication style). In addition, adolescents reported greater perceived legitimacy and less oppositional defiance in the moral domain (as compared to the friendships domain). Second, we tested whether associations between degree and style of prohibition and the developmental outcomes were moderated by social domain. Whereas associations between degree of prohibition and developmental outcomes either were non-significant or moderated by domain, the associations with communication style were more domaininvariant, with an autonomy-supportive style generally yielding an adaptive pattern of correlates and with a controlling style relating to maladaptive outcomes. The discussion focuses on similarities and differences in the characteristics and correlates of both types of prohibitions.
\end{abstract}

KEYWORDS: prohibition; social-cognitive domain theory; self-determination theory; internalization; defiance; legitimacy; parenting 


\section{Introduction}

A central task for parents in the socialization process is to teach children about behaviors that are appropriate and allowed and about behaviors that are undesirable and forbidden (e.g., Kochanska, Aksan, \& Koenig, 1995; Maccoby, 2007). To prevent children from engaging in undesirable (e.g., immoral or dangerous) behaviors, parents need to set clear limits, thereby prohibiting inappropriate behavior. Effective socialization involves children's internalization (i.e., self-endorsement) of these limits and of the associated societal norms and values (Grusec \& Goodnow, 1994). In contrast, the failure to socialize children is reflected in children's rejection of the introduced limits and in the perception that their parents' authority is illegitimate (Tyler, 2006). However, as forbidden fruits are often said to be more attractive (e.g., Keijsers et al., 2012), an important question is whether it is always wise for parents to prohibit undesirable behavior. That is, prohibitions might backfire, thereby eliciting the opposite behavior (Sheikh \& Janoff-Bulman, 2013). This may be particularly the case during adolescence, which constitutes a developmental period during which parental rules - and authority in general - is challenged more often (Arnett, 1999; Steinberg \& Morris, 2001).

Longitudinal research grounded in Self-Determination Theory (Ryan \& Deci, 2000) has provided insight in the conditions that determine when parental prohibitions are effective. Specifically, the way in which prohibitions are introduced and conveyed (i.e., the communication style) appeared more critical than the degree of prohibitions per se, with an autonomy-supportive communication style predicting more favorable outcomes than a controlling style (Vansteenkiste, Soenens, Van Petegem, \& Duriez, 2014). However, relatively less is known about whether the effectiveness of prohibitions also depends on the domain at stake. Herein, we drew upon Social-Cognitive Domain Theory (Nucci, 1996; Smetana, 2006; Turiel, 1983) to compare parental prohibitions of immoral behavior versus 
friendship issues. We chose these two domains because the former domain often is seen as falling under the parents' authority, whereas the latter domain rather would fall under the adolescents' personal jurisdiction (e.g., Kuhn, Phan, \& Laird, 2014; Smetana \& Asquith, 1994).

The overall goal of the current multi-informant study is to examine simultaneously the role of social domain and maternal communication style in adolescents' responses to maternal prohibitions. The study had two specific aims. The first aim involved assessing mean-level differences between friendship and moral prohibitions in terms of both the degree of prohibitions and the communication style about these prohibitions. We also examined meanlevel differences in important developmental outcomes that reflect (un)successful socialization of parental prohibitions, that is, adolescents' perceived legitimacy, internalization of and oppositional defiance to these prohibitions. The second aim was to examine the relations between the mothers' degree and style of prohibition and these developmental outcomes and to test whether social domain would moderate these associations.

\section{Perceived Legitimacy, Internalization and Oppositional Defiance}

Adolescents differ significantly in their perceptions of their parents as having the legitimate authority to set certain rules, restrictions, and expectations about their behavior (e.g., Kuhn \& Laird, 2011). Legitimacy reflects an important psychological feature of an authority or socialization figure, because people are more likely to voluntarily defer to decisions, rules, and standards introduced by authority figures who are perceived as fair and as having legitimate authority (Tyler, 2006). Indeed, numerous studies in diverse fields showed that, the more people perceive an authority as having the legitimate right to set certain rules, the more they are willing to obey the introduced rules and the more they have favorable perceptions of the authority figure (e.g., Mazerolle, Bennett, Davis, Sargeant, \& Manning, 2013; Sunshine \& Tyler, 2003). 
Applied to the parent-child relationship, when children perceive their parents as having the legitimate authority to set rules, they are less likely to violate them (Kuhn et al., 2014). Indeed, several studies have found that adolescents with greater perceptions of legitimate parental authority exhibited less problem behavior and were less involved with antisocial peers (e.g., Cumsille, Darling, Flaherty, \& Martinez, 2009; Kuhn \& Laird, 2011; Trinkner, Cohn, Rebellon, \& Van Gundy, 2012). Importantly, adolescence is characterized by a normative decrease in adolescents' beliefs about the legitimacy of parental authority (Darling, Cumsille, \& Martinez, 2008; Smetana, 2000). Notwithstanding this average decline in legitimacy beliefs, there remains substantial variability between adolescents in their perceptions of legitimacy (Cumsille et al., 2009). Therefore, it is critical to determine which parental factors relate to adolescents' perceptions of their parents as having the legitimate authority to set rules and to prohibit certain behaviors.

Another indicator of successful socialization is internalization, which refers to the gradual acceptance and self-endorsement of parental rules and prohibitions (Grusec \& Goodnow, 1994; Maccoby, 2007). When a rule is internalized, behavior consistent with the rule will be enacted out of personal conviction and with a sense of volition and psychological freedom, as one endorses and understands the value of the rule (Kochanska et al., 1995; Ryan $\&$ Deci, 2000). To conceptualize internalization, we drew upon Self-Determination Theory (Ryan \& Connell, 1989; Ryan \& Deci, 2000), which distinguishes different reasons for following norms varying along a continuum of increasing self-endorsement and internalization. External regulation reflects a total lack of internalization as adolescents merely comply with parental prohibitions for externally pressuring reasons. For instance, adolescents may stick to the prohibition because they feel threatened by punishments or because they feel seduced by an externally offered reward. Introjected regulation reflects partial internalization, as adolescents have begun to accept the parental prohibition, but it is 
not yet fully endorsed by the self. In this case, adolescents stick to parental prohibitions out of internally pressuring reasons, such as to avoid feelings of guilt or shame or to derive a sense of self-worth by acting like a model child (see e.g., Crocker \& Park, 2004; Van der KaapDeeder et al., 2016). Finally, identified regulation reflects the full acceptance or internalization of the rule. In this case, adolescents follow a prohibition because they personally endorse and fully understand the value and importance of the prohibition.

In sum, these three different types of reasons vary in their degree of internalization, with external, introjected and identified regulation being indicative of, respectively, the total absence, partial presence and full presence of internalization. The more a rule or prohibition is internalized, the more one is likely to persist in rule-compatible behavior (Kochanska et al., 1995; Ryan \& Deci, 2000). Indeed, several scholars (e.g., Grolnick, Deci, \& Ryan, 1997; Grusec \& Goodnow, 1994; Kochanska, 2002; Ryan \& Deci, 2000) have emphasized the crucial importance of internalization, as it represents the key route to children's sustained adherence to rules and expectations, even in the absence of socialization figures. Demonstrating the developmental importance of internalization, several studies have found that greater internalization is related to less problem behavior, long-term persistence, and more prosocial behavior in adolescents (e.g., Pelletier, Fortier, Vallerand, \& Briere, 2001; Ryan \& Connell, 1989; Soenens, Vansteenkiste, \& Niemiec, 2009; Vallerand, Fortier, \& Guay, 1997). Moreover, previous research has suggested that the internalization of rules generally increases when children grow older, although these studies mainly have been conducted among younger children (e.g., Chandler \& Connell, 1987; Kochanska et al., 1995).

A third developmental outcome relevant to socialization is adolescents' oppositional defiance, which involves a blunt rejection of the parents' prohibitions and a tendency to do the opposite of what is expected (Deci \& Ryan, 1985; Skinner \& Edge, 2002; Vansteenkiste et al., 2014). Oppositional defiance can be distinguished from more constructive types of 
resistance within the parent-child relationship (e.g., Kuczynski \& Hildebrandt, 1997; Smetana, 2005). Children's negotiation about parental requests, for instance, reflects a more adaptive strategy of expressing resistance, where the child constructively articulates disagreement by engaging in a dialogue (Parkin \& Kuczynski, 2012; Skinner \& Edge, 2002). Previous studies among both younger children (e.g., Kuczynski \& Kochanska, 1990) and adolescents (e.g., Parkin \& Kuczynski, 2012) have indicated that different types of resistance manifest differently, serve different goals and are characterized by different developmental trajectories.

In this context, oppositional defiance was found to represent an unskillful way of expressing resistance. This is because oppositional defiance involves the tendency to directly defy to the authority figure as such and to do the exact opposite of what is expected. Although adolescents display oppositional defiance in an attempt to regain a sense of freedom, rather ironically, it may alienate them from their personal interests and preferences (Pavey \& Sparks, 2009; Van Petegem, Vansteenkiste, Soenens, Beyers, \& Aelterman, 2015). In other words, this type of resistance is reactive (rather than reflective) in nature, as the primary goal is to oppose to the parents' wishes (Koestner \& Loesier, 1996). Research has documented associations between oppositional defiance and the rejection of parental rules (e.g., Baudat, Zimmermann, Antonietti, \& Van Petegem, 2016), an increasing distance in the parentadolescent-relationship (Van Petegem, Vansteenkiste, et al., 2015), and more adolescent internalizing and externalizing symptoms (e.g., Van Petegem, Soenens, Vansteenkiste, \& Beyers, 2015).

\section{Parents' Communication Style}

On the basis of Self-Determination Theory (Deci \& Ryan, 2000), it can be expected that parents' communication style, which pertains to the way in which parents introduce and talk about rules and prohibitions, plays an important role when predicting the aforementioned developmental outcomes. A key and relevant distinction is between an autonomy-supportive 
and a controlling communication style (Soenens \& Vansteenkiste, 2010). An autonomysupportive communication style involves asking for the child's input and empathizing with the perspective of the child, offering choice about how certain expectations can be met, and providing a meaningful explanation for rules and prohibitions (Grolnick, 2003; Soenens et al., 2007). When being controlling, parents force the child to comply with their demands, for instance through the use of forceful language, guilt induction and threats with punishment (Barber, 1996; Grolnick \& Pomerantz, 2009).

A few previous studies already have examined the role of parents' communication style with respect to prohibitions and rules. These studies have found that an autonomysupportive style relates positively to internalization of parental rules and child adjustment more generally, whereas a controlling style relates to an absence of internalization and even oppositional defiance to the parents' rules and prohibitions (Soenens et al., 2009; Van Petegem, Soenens, et al., 2015; Vansteenkiste et al., 2014). Similarly, an autonomysupportive parenting style has been found to relate positively to legitimacy perceptions about parental authority (Trinkner et al., 2012). Relatedly, Darling et al. (2008) have found that stronger legitimacy beliefs were related to adolescents' general perceptions of their parents as highly supportive and as often supervising their activities. Building upon this work, we focused specifically on the issue of parental prohibitions, thereby examining whether these processes operate similarly or differently in different social domains.

\section{Moral Prohibitions vs. Friendship Prohibitions}

To address the question whether adolescents' responses also depend upon the content of what is prohibited, we drew upon Social-Cognitive Domain Theory (Smetana, 2006). This theory states that, from early childhood on, children construct different types of social knowledge systems (or social domains), which they apply in their interpretation of the social world. Depending upon the social domain at stake (e.g., moral, personal), children would 
reason fundamentally differently about obedience, transgression, and legitimate jurisdiction (Lagatutta, Nucci, \& Bosacki, 2010; Nucci, 1981; Smetana, 2005). The moral domain pertains to prescriptive rules and norms about rights, justice and others' welfare (e.g., whether one can lie or hit others; Smetana, 2006). Both parents and children generally agree that parents have the legitimacy to regulate these moral issues throughout adolescence (e.g., Smetana, 2000; Smetana \& Asquith, 1994; Smetana, Crean, \& Campionne-Barr, 2005). The personal domain comprises private aspects of one's life, such as the choice of clothes, hairstyle, and peer relationships. As these issues reflect aspects of adolescents' identity and, hence, delineate the boundary between the self and the social world, adolescents claim that these issues need to be regulated by themselves rather than by parents (Nucci, 2001; Smetana, 2005).

Consistent with the idea that parents and adolescents reason differently about issues in the moral as compared to the personal domain, previous studies have documented betweendomain mean-level differences in both parents' and adolescents' beliefs about parents having the legitimate authority for rule-setting, with legitimacy perceptions being elevated for rulesetting about moral issues, as compared to personal issues such as friendships (e.g., Smetana \& Asquith, 1994; Smetana, 2000; Tisak, 1986). To the best of our knowledge, however, no formal domain-comparisons have been made with regard to prohibitions in particular, nor regarding parents' style of communicating prohibitions. Theoretically, it is assumed that parents are generally involved more strongly in the moral domain as compared to the personal domain (Smetana, 1999). This stronger involvement can be expressed not only through a higher degree of rule-setting as such, but also through both more autonomy-supportive and more controlling communication about moral (as compared to friendship-related) prohibitions. Indirectly supporting this claim, Arim, Marshall, and Shapka (2010) found that adolescents perceived higher scores for parental behavioral control (i.e., a mixture of clear rule-setting and 
severe controlling strategies, such as punishing) for moral issues, as compared to friendship issues. Similarly, Padilla-Walker and Carlo (2006) found that parental yelling and punishments - two controlling responses - are especially prevalent in response to moral transgressions, compared to other types of transgressions. Drawing upon theory and these findings, we expected to find stronger legitimacy beliefs, a higher occurrence of maternal prohibitions, and more maternal engagement in both an autonomy-supportive and a controlling communication style in the moral domain, as compared to the friendship domain.

Further, we also sought to examine whether adolescents would exhibit more internalization and less oppositional defiance in response to moral, relative to friendshiprelated, prohibitions. This is because adolescents generally would consider parental involvement in the moral domain as legitimate and would be more likely to endorse parents' moral authority (Smetana, 2005). Indirectly supporting this claim, previous research has reported more parent-adolescent conflict (e.g., Smetana, 1989) and more adolescent secrecy (e.g., Smetana, Villalobos, Rogge, \& Tasopoulos-Chan, 2010) about friendship issues, as compared to moral issues. Yet, no previous studies explicitly have examined possible meanlevel differences between the friendship and the moral domain in adolescents' internalization and oppositional defiance in response to parental prohibitions.

In addition to examining mean-level differences, we also examined associations of mothers' degree of prohibition and their style of communicating prohibitions with each of the developmental outcomes. In doing so, we tested whether these associations would be moderated by social domain. Previous research indicates that rule-setting in the personal domain especially is perceived as intrusive and autonomy-inhibiting (e.g., Smetana \& Daddis, 2002; Soenens, Vansteenkiste, Smits, Lowet, \& Soenens, 2007), and that parental regulation of friendships is associated with more deviant friendship affiliations and more externalizing problems (e.g., Keijsers et al., 2012; Mounts, 2001). Drawing upon this work, we expected 
that associations between degree of prohibition and the developmental outcomes would be moderated by domain, such that a higher degree of prohibitions in the friendship domain would relate to weaker legitimacy perceptions, more oppositional defiance, and less internalization, whereas an opposite pattern of correlates was expected to emerge in the moral domain.

However, we hypothesized that the correlates of mothers' communication styles would be domain-invariant, with a controlling style relating to weaker legitimacy perceptions, less internalization, and more oppositional defiance, and with an autonomy-supportive style showing the opposite pattern of results in both domains. Indeed, autonomy-supportive strategies (such as reasoning and offering a meaningful rationale) would facilitate development and internalization across domains (e.g., Grolnick et al., 2014), whereas controlling and power-assertive strategies would be detrimental across different contexts (e.g., Hoffman, 2000; Soenens \& Vansteenkiste, 2010). Padilla-Walker and Carlo (2006) provided preliminary support for this hypothesis by showing that, although controlling parental reactions were more common in the moral domain compared to other domains, a higher frequency of such reactions related negatively to adolescent ratings of appropriateness across domains.

\section{The Present Study}

Drawing upon both Social-Cognitive Domain Theory (Smetana, 2006) and SelfDetermination Theory (Deci \& Ryan, 2000), the present study had two general goals. First, we aimed to examine mean-level differences between the moral domain and the friendship domain in mothers' degree of prohibition, in their style of communicating about these prohibitions and in a number of developmental outcomes (i.e., perceived legitimacy, internalization, oppositional defiance; Research Question 1). Reflecting parents' greater involvement in the moral domain, we hypothesized that mothers would display a higher 
degree of prohibition, as well as a more frequent use of both a controlling and autonomysupportive style when communicating about moral prohibitions, as compared to friendship prohibitions. Further, we hypothesized that adolescents would report greater legitimacy perceptions, more internalization, and less oppositional defiance to prohibitions in the moral domain, as compared to the domain of friendships.

Second, we aimed to examine associations between mothers' degree and style of prohibition and the developmental outcomes, thereby testing whether social domain moderated these associations (Research Question 2). We expected that social domain would moderate the associations of degree of prohibition, with mothers' degree of prohibition being more adaptive in the moral domain than in the friendship domain. By contrast, we hypothesized that the correlates of mothers' communication style would be relatively similar across the two domains, with an autonomy-supportive style relating to more desirable outcomes and with a controlling style relating to less desirable outcomes.

To the best of our knowledge, this is the first study to address these questions specifically with regard to maternal prohibitions and explicitly contrasting the moral domain with the friendship domain. Moreover, the present study also had two methodological strengths, that is, (a) the reliance on multi-informant information, which allowed to circumvent potential problems related to shared method variance, and (b) the use of a withinsubjects design, which allowed to circumvent possible error caused by naturally occurring variance between groups (Charness, Gneezy, \& Kuhn, 2012). Being one of the first studies to formally compare the occurrence and correlates of parents' degree of prohibition and their communication style, we focused on mothers. In spite of important sociological changes leading to increased paternal involvement in child rearing, on average mothers still are more strongly involved in children's and adolescents' lives (Bornstein, 2015). This is also the case 
in Belgium, the country in which this study was conducted, as especially mothers are strongly involved in daily interactions with their adolescent children (Goossens \& Luyckx, 2007).

Finally, given that several previous studies documented age-related differences in, for instance, legitimacy beliefs (e.g., Darling et al., 2008; Smetana, 2000) and oppositional defiance (e.g., Van Petegem, Vansteenkiste, et al., 2015), we controlled for age group (i.e., early vs. middle adolescence) throughout our analyses. Moreover, as a supplementary set of analyses, we also tested whether age group moderated the above relations. Given that the personal domain expands throughout the adolescent years (e.g., Darling et al., 2008; Smetana et al., 2005), it could be expected that the correlates of maternal prohibitions of friendships are even more maladaptive (i.e., relating to less perceived legitimacy, less internalization, and more oppositional defiance) among older, when compared to younger, adolescents. Further, we also controlled for adolescents' gender in our analyses. As gender socialization theories suggest that girls are encouraged to be sensitive and cooperative, whereas boys are expected to be more independent and dominant (Beal, 1994; Galambos, Berenbaum, \& McHale, 2009), gender differences may be observed in variables such as adolescents' legitimacy beliefs and oppositional defiance. Similarly, some studies indicated gender differences in psychologically controlling parenting (with, for instance, boys reporting more maternal psychological control; e.g., Soenens, Luyckx, Vansteenkiste, Duriez, \& Goossens, 2008), yet other studies found no gender differences (e.g., Mandara \& Pikes, 2008; Morris, Steinberg, Sessa, Avenevoli, Silk, \& Essex, 2002; Rogers, Buchanan, \& Winchell, 2003).

\section{Method}

\section{Sample and Procedure}

Data for the present study were gathered through a secondary school in a mid-sized city in the Dutch-speaking part of Belgium. Pupils from all grades (i.e., $7^{\text {th }}$ through $12^{\text {th }}$ grade; all academic track) were invited to participate. During a class period, we distributed 500 
envelopes among all pupils of the school. The envelope contained one questionnaire for the adolescent and one for the mother. Participants were invited to complete the questionnaire at home and to return the closed package with questionnaires if both the adolescent and mother questionnaire were completed. Informed consents were obtained. We guaranteed the anonymous treatment of the data and explained that participation was voluntary. No incentives for participation were offered. This procedure was in line with the ethical guidelines formulated by the ethical board of the host institution.

In total, we obtained data from 196 adolescents (124 girls; 63.3\%), yielding a response rate of $39.2 \%$. The mean age was 13.86 years $(S D=1.51$, range $=12-17$ years $)$, with 42 participants $(21.4 \%)$ from $7^{\text {th }}$ grade, 50 participants $(25.5 \%)$ from $8^{\text {th }}$ grade, 35 participants (17.9\%) from $9^{\text {th }}$ grade, 35 participants $(17.9 \%)$ from $10^{\text {th }}$ grade, 21 participants $(10.7 \%)$ from $11^{\text {th }}$ grade, and 13 participants $(6.6 \%)$ from $12^{\text {th }}$ grade. For age-related analyses, we split our sample into early adolescents (12-14 years; $N=131)$ and middle adolescents (15-17 years; $N$ $=65$; cf. Berk, 2014). Information regarding ethnicity was not available, but pupils from the participating school mostly had the Belgian nationality and were all Dutch-speaking. Eightythree percent of the participants came from intact families, $14 \%$ had divorced parents, and 3\% came from a family with a deceased parent. In addition, we obtained data from 185 mothers, whose mean age was 44 years $(S D=3.50$, range $=36-56$ years $)$. In terms of highest level of education, $11 \%$ of the mothers had obtained a primary school degree, $24 \%$ a secondary school degree, and $65 \%$ a college or university degree. In total, $2.5 \%$ of the data was missing. Little's (1988) MCAR-test suggested that these missing values were randomly missing (normed $\chi^{2}=$ $1.24, n s)$, and therefore were imputed through the Expectation Maximization (EM) procedure (Schafer, 1997).

\section{Measures}


Both adolescents and mothers filled out the scales assessing maternal degree and style of prohibition. The scales that assess perceived legitimacy, internalization, and oppositional defiance were administered to the adolescents only.

Degree of prohibition, perceived legitimacy, and communication style. Mothers and adolescents reported upon mothers' degree of prohibition and their style of communicating about friendship and moral prohibitions, and adolescents also reported upon their perceived legitimacy of these prohibitions. Participants first rated the degree to which mothers prohibit friendships through a 5-item questionnaire developed by Soenens et al. (2009) (e.g., "My mother does not allow me to hang out with some friends"). Statements were slightly modified to make them amenable for parent reports (e.g., "I don't allow my child to hang out with some friends"). Participants responded on a 5-point Likert-type scale $(1=$ totally disagree, $5=$ totally agree $)$.

Following each prohibition statement, perceived legitimacy and maternal communication style were evaluated. First, adolescents reported on their perceptions of their mother having the legitimate authority for setting these prohibitions, by indicating the degree to which they thought it was OK for mothers to set these prohibitions (Kuhn \& Laird, 2011; Smetana \& Asquith, 1994). Then, both mothers and adolescents were presented items measuring maternal communication style. Specifically, after each prohibition statement, one item assessed an autonomy-supportive style (resulting in 5 items in total; e.g., "My mother would give a meaningful explanation for why she thinks this is important"), and two items assessed a controlling style (resulting in 10 items in total; e.g., "My mother would say she will be very disappointed with me if I disobey"). Again, mothers answered the same items with minor revisions in wording (e.g., "I would give a meaningful explanation for why I think this is important"). Participants again responded on a 5-point Likert-type scale (1 = totally 
disagree, 5 =totally agree). The same questionnaires were then repeated with a focus on mothers' prohibition of morally inappropriate behaviors (e.g., lying, stealing).

Extensive validity information for this measure was provided by Soenens et al. (2009) and Vansteenkiste et al. (2014), who showed that the scales related in theoretically predicted ways to more general measures of autonomy-supportive and controlling parenting style. In terms of predictive validity, they also found, for instance, that a controlling style of friendship prohibitions was related to more affiliation with deviant peers and more involvement in problem behaviors, whereas the opposite pattern of correlates was found for an autonomysupportive style (Soenens et al., 2009). In the present investigation, internal consistencies were .76 and .87 for adolescent-reported degree of prohibition (for the friendship and the moral domain, respectively), .82 and .89 for mother-reported degree of prohibition, .89 and .85 for adolescent-reported and .89 and .86 for mother-reported autonomy-supportive style communication style, .85 and .83 for adolescent-reported and .85 and .85 for motherreported controlling communication style, and .89 and .90 for perceived legitimacy.

Internalization. Adolescents' internalization of their mother's prohibitions was measured with the Self-Regulation Questionnaire-Parental Rules (Soenens et al., 2009), which was filled out separately for rules about friendships and about moral issues. This 18item scale measures adolescents' reasons for following their mother's rules, and more specifically, it measures adolescents' identified regulation (6 items; e.g., "because I find these rules personally meaningful"), introjected regulation (6 items, e.g., "because I would feel guilty if I would not do so"), and external regulation (6 items, e.g., "because otherwise I will be punished") for following their mother's rules. Items were rated on a 5-point Likert-type scale $(1$ = completely disagree, 5 = completely agree $)$. Internal consistencies were .89 and .91 for identified regulation (for the friendship and the moral domain, respectively), .83 and .85 for introjected regulation, and .80 and .82 for external regulation. 
Given that these three types of regulation are situated on a continuum of internalization, they are supposed to form a quasi-simplex pattern (Guttman, 1958), where subscales next to each other on the internalization continuum (i.e., identified and introjected regulation; introjected and external regulation) would be more strongly correlated that those further apart (i.e., identified and external regulation). This quasi-simplex pattern was indeed observed, with identified regulation being positively related to introjected regulation $(.63, p$ $<.001$, and $.70, p<.001$, for the friendship and the moral domain, respectively) and unrelated to external regulation $(.09, n s$, and $.08, n s$, respectively), and with introjected and external regulation also being positively related $(.45, p<.001$, and $.33, p<.001$, respectively). Such a pattern of correlations suggests that introjected regulation lies in between identified and external regulation on the continuum of internalization, providing evidence for the internal validity of the scale and justifying the creation of a summarizing Relative Internalization Index (RII; see also Soenens et al., 2009; Vallerand et al., 1997). This index was calculated by assigning a weight to each subscale, depending on their place on the internalization continuum. In line with previous studies (e.g., Fousiani, Van Petegem, Soenens, Vansteenkiste, \& Chen, 2014; Neyrinck, Vansteenkiste, Lens, Duriez, \& Hutsebaut, 2006; Soenens et al., 2009), scores for identified, introjected, and external regulation were weighted with $+3,-1$, and -2 , respectively. These weighted scores were summed to create an overall composite score, with higher scores reflecting more internalization. Previous research offered evidence for the external validity of this measure, for instance by showing that a greater internalization of parental rules relates to less problem behavior (e.g., Soenens et al., 2009).

Oppositional defiance. We assessed oppositional defiance through a 4-item questionnaire (Vansteenkiste et al., 2014), which evaluates adolescents' rejection of their mother's rules and their tendency to do exactly the opposite. This scale was also filled out separately for friendship rules and moral rules (e.g., "I rebel against my mother's rules for 
unacceptable behavior"). Items were measured on a 5-point Likert-type scale $(1=$ completely disagree to $5=$ completely agree). As in previous research (e.g., Vansteenkiste et al., 2014), internal consistencies were excellent (i.e., .87 for both the friendship and the moral domain). Moreover, previous studies (e.g., Van Petegem, Soenens, et al., 2015) provided evidence for the external validity of the present measure, as higher scores were related to the rejection of parental requests and to more externalizing symptoms.

\section{Results}

\section{Research Question 1: Mean-Level Differences}

Correlations between the study variables can be found in Table 1. First, we tested whether there were mean-level differences in terms of the degree of prohibition and communication style as a function of social domain (friendship vs. moral) and informant (adolescent vs. mother). In doing so, we also controlled for gender and age group. This was done through a repeated measure ANOVA with gender and age group as between-subject variables, and with domain and informant as within-subject variables as well with the domain $\times$ informant interaction term, the gender-related interaction terms (i.e., gender $\times$ domain, gender $\times$ informant, gender $\times$ domain $\times$ informant) and the age-related interaction terms (i.e., age $\times$ domain, age $\times$ informant, age $\times$ domain $\times$ informant) as within-subject variables Degree of prohibition, autonomy-supportive style, and controlling style were the dependent variables. The multivariate effects of informant $\left[F(3,190)=26.09, p<.001, \eta^{2}=.29\right]$ and domain $\left[F(3,190)=307.64, p<.001, \eta^{2}=.82\right]$ were statistically significant, as was the interaction between domain and informant $\left[F(3,190)=4.66, p=.004, \eta^{2}=.07\right]$. The main effects of gender and age group were not significant $[F(3,190)=2.39, p=07$, for gender; $F(3,190)=1.35, p=.26$, for age group], nor were the interactions with gender and age $[F(3,193)=2.06$ or lower, $p$-values between .11 and .20 , for gender; $F(3,190)=.87$ or lower, $p$-values between .46 and .73 , for age group], suggesting that there were no gender-related or 
age-related effects. As can be noticed in Table 2, at the univariate level, informant differences were found for degree of prohibition $\left[F(1,192)=19.17, p<.001, \eta^{2}=.09\right]$, autonomysupportive style $\left[F(1,192)=65.72, p<.001, \eta^{2}=.26\right]$ and controlling communication style $\left[F(1,192)=4.82, p=.03, \eta^{2}=.03\right]$, with mothers reporting higher scores than adolescents on each of these variables. With respect to domain, significant mean-level differences were found for degree of prohibition $\left[F(1,192)=813.21, p<.001, \eta^{2}=.81\right]$ and controlling communication style $\left[F(1,192)=233.44, p<.001, \eta^{2}=.55\right]$, effects that were not moderated by informant. This pattern suggests that, regardless of the informant, there is a higher prevalence of prohibitions and of controlling communication in the moral domain, as compared to the friendship domain. Although no main effect of domain was found for an autonomy-supportive communication style $[F(1,192)=.01, p=.92]$, the interaction between domain and informant was significant $\left[F(1,192)=12.58, p<.001, \eta^{2}=.06\right]$. Whereas adolescents perceived their mothers to be relatively more autonomy-supportive in the friendship domain, mothers reported relatively more autonomy support in the moral domain.

Then, we tested for between-domain mean-level differences in perceived legitimacy, internalization, and oppositional defiance, thereby also controlling for gender and age group. This was also done through a repeated-measures MANOVA with gender and age group as between-subject variables, and with domain, the gender $\times$ domain interaction term and the age $\times$ domain interaction term as within-subject variables. This analysis yielded a statistically significant multivariate effect of social domain $\left[F(3,190)=52.51, p<.001, \eta^{2}=.45\right]$. The effects of gender and age group were not significant $[F(3,190)=1.40, p=.24$, for gender; $F(3,190)=1.01, p=.39$, for age group], nor were the interaction terms with gender or age group $[F(3,190)=1.39, p=.25$, for gender $\times$ domain; $F(3,190)=.62, p=.61$, for age $\times$ domain], suggesting an absence of gender-related or age-related differences. Subsequent univariate analyses uncovered between-domain mean-level differences for perceived 
legitimacy $\left[F(1,192)=146.13, p<.001, \eta^{2}=.43\right]$ and for oppositional defiance $[F(1,192)=$ 28.39, $\left.p<.001, \eta^{2}=.13\right]$, but not for internalization $[F(1,192)=.06, p=.81]$. As can be seen in Table 2, adolescents reported stronger legitimacy perceptions and less oppositional defiance in the moral domain, as compared to the friendship domain.

\section{Research Question 2: The Correlates of Degree and Style of Prohibition}

The second research question involved examining the relation between mothers' degree and style of prohibition and adolescents' developmental outcomes, and whether this relation was moderated by social domain. This was done through linear mixed modelling (West, Welch, \& Galecki, 2014) in R Version 3.2.2 (R Development Core Team, 2014). This analytical procedure allowed us to estimate the relation between degree and style of prohibition and the developmental outcome across social domains, as well as to test directly whether social domain moderated this association. Specifically, we performed six analyses (three outcomes * two informants), each time specifying degree and autonomy-supportive and controlling style of prohibition as between-subject predictors, and social domain as a withinsubject predictor. We also included the three interaction terms between domain and degree/style of prohibition and we controlled for gender and age group. A summary of these results can be found in Table 3 .

The first set of analyses, focusing on perceived legitimacy, indicated a statistically significant association with adolescent-reported degree of prohibition; however, this association was moderated by social domain, such that a higher degree of prohibition related positively to perceived legitimacy in the moral domain but was unrelated in the friendship domain (see Figure 1A). Mother-reported degree of prohibition was not significantly related to perceived legitimacy, nor was there an interaction with social domain. Across informants and across domains, the associations with autonomy-supportive communication style were statistically significant, such that higher scores on autonomy-supportive style were related to 
stronger legitimacy perceptions. Associations with controlling communication style were not statistically significant.

The next set of analyses examined associations with adolescents' internalization. Neither adolescent-reported nor mother-reported degree of prohibition was statistically significantly associated. However, adolescent-reported (but not mother-reported) autonomysupportive communication style did relate positively to adolescents' internalization. Also in line with our expectations, we found that, across informants, controlling communication style related negatively to adolescents' internalization. None of these relations were moderated by social domain.

In the third set of analyses, we examined the associations with oppositional defiance. In line with our hypotheses, we found that the association between adolescent-reported degree of prohibition and oppositional defiance was moderated by social domain, with a higher degree of prohibition being positively related to oppositional defiance in the friendships domain but not in the moral domain (see Figure 1B). The relation with mother-reported degree of prohibition did not reach statistical significance. Further, an autonomy-supportive communication style related to less oppositional defiance, an association that was found across informants. Finally, the association with adolescent-reported controlling communication style was moderated by domain, such that a controlling style significantly related to more oppositional defiance in the friendship domain only (see Figure 1C). The association with mother-reported controlling communication style was not significant.

\section{Supplementary Analyses: The Moderating Role of Age}

As a supplementary set of analyses, we tested whether age group moderated the above relations. This was done by re-running each of the six linear mixed models, thereby adding the three second-order interaction terms (i.e., age $\times$ degree, age $\times$ autonomy-support, age $\times$ control) and three third-order interaction terms (i.e., age $\times$ domain $\times$ degree, age $\times$ domain $\times$ 
autonomy-support, age $\times$ domain $\times$ control). However, none of these interaction terms reached significance ( $t$-values ranging between -1.70 and 1.39 , all $n s)$ suggesting that the previously found associations do not differ for early vs. middle adolescents.

\section{Robustness of the Findings}

We performed two additional sets of analyses to examine the robustness of our findings. In a first set of additional analyses, we re-examined the association between degree and style of prohibition and internalization, thereby performing the analyses separately for each of the subscales of our internalization measure. In general, there was strong convergence between the findings obtained with the composite score of internalization and the findings obtained with the subscales. For instance, an autonomy-supportive communication style was associated positively with identified regulation (which reflects high levels of internalization) and negatively with external regulation (which reflects an absence of internalization), and a controlling communication style yielded an opposite pattern of associations. Associations between degree of prohibition and the separate regulation types were less consistent, which is also reflected in the non-significant association with the overall score for internalization. The second set of additional analyses involved another approach to testing the moderating role of social domain. Specifically, we ran 12 regression analyses ( 2 domains $* 2$ informants $* 3$ outcomes), and then directly and formally compared differences in strength of the standardized regression coefficients for the moral as opposed to the friendship domain. This comparison was done through the use of a bootstrapping procedure (Manly, 2006) with 10,000 bootstrap samples, thereby taking into account the repeated measures design. The associations obtained in these analyses also strongly converged with our linear mixed modeling analyses, mainly yielding evidence for between-domain differences in the associations of degree of prohibition with legitimacy and oppositional defiance. The results of these analyses can be obtained upon request. 


\section{Discussion}

Especially during adolescence, setting rules and communicating prohibitions may be challenging for parents. This is because, during this life period, the parent-adolescent relationship undergoes a significant transformation and adolescents seek to renegotiate the boundaries of what falls under their personal jurisdiction (e.g., Buchanan et al., 1990; Smetana et al., 2005). Although quite a number of previous studies focused on the issue of parental rule-setting in general, the current multi-informant study adds significantly to the literature by focusing specifically on maternal prohibitions and by explicitly and formally contrasting the occurrence and correlates of prohibitions in two important social domains, that is, the moral domain and the friendship domain. The current contribution drew upon two prominent theories on socialization that have not been studied together very often, that is, Social-Cognitive Domain Theory (Nucci, 1996; Smetana, 2006; Turiel, 1983) and SelfDetermination Theory (Ryan \& Deci, 2000), which allowed for a nuanced and multiperspective examination of the issue of parental prohibitions and for the inclusion of a broad range of important developmental outcomes.

In line with Social-Cognitive Domain Theory, the present study showed that it is important to consider what parents prohibit. Indeed, adolescents were more likely to accept maternal prohibitions about moral issues, such as lying or stealing, as compared to prohibitions about friendships; that is, they reported higher scores on internalization and perceived legitimacy and lower scores on oppositional defiance to moral prohibitions. Also, both adolescents and mothers reported more maternal involvement in the moral domain, as manifested in the higher prevalence of moral prohibitions and in mothers' more frequent use of a controlling style in the moral domain.

Moreover, the present study also showed that it is important to consider how prohibitions are communicated. In line with Self-Determination Theory, we found that, across 
domains and informants, an autonomy-supportive communication style generally related to a number of indicators of effective socialization (i.e., more internalization and greater legitimacy perceptions, less oppositional defiance), whereas a controlling communication style was associated with the opposite pattern of correlates. Additionally, these associations were not moderated by the adolescents' age. Specific findings are outlined in detail below.

\section{Mean-Level Differences between Domains}

The first aim of the present study was to test for mean-level differences between the moral domain and the friendship domain, both in terms of the degree and style of prohibition, as well as in terms of perceived legitimacy, internalization and oppositional defiance displayed by adolescents in response to these prohibitions. First, both mothers and adolescents seemed to agree that mothers were more involved in the moral domain, as reflected in the presence of more prohibitions in the moral domain and in the more frequent use of a controlling style when communicating about moral issues. These results are complementary with findings from previous studies showing that adolescents generally perceive more behavioral control in the moral domain (Arim et al., 2010) and that adolescents report more parental yelling and punishing in response to moral transgressions, as compared to other types of transgressions (Padilla-Walker \& Carlo, 2006). Theoretically, this greater maternal involvement in the moral domain is congruent with the fact that parents often are strongly concerned with their children's moral development (e.g., Hoffmann, 2000; Smetana, 1999), whereas friendship issues are rather considered to fall under the adolescents' personal jurisdiction.

To the best of our knowledge, no previous research to date examined between-domain differences in the use of autonomy support. Our findings for an autonomy-supportive communication style were informant-dependent. Specifically, mothers reported being more autonomy-supportive with respect to moral prohibitions than with respect to friendships, 
which is again in line with the notion that parents would be strongly involved in adolescents' moral development (Smetana, 1999). The adolescents themselves, however, reported more maternal autonomy support when communicating about friendship issues as compared to moral issues. This discrepancy may reflect a perceptual bias, with different informants noticing, interpreting, and recalling the same interactions differently (De Los Reyes, 2013). Specifically, whereas mothers intend to be autonomy-supportive when discussing moral prohibitions, adolescents do not necessarily perceive maternal communication about these prohibitions as autonomy-supportive. More generally, this discrepancy points to the importance of considering multiple sources of information when investigating family dynamics (see also Rote \& Smetana, 2016).

Further, we obtained clear evidence that adolescents believe that their mothers have greater legitimate authority to set prohibitions about moral issues as opposed to friendship issues. This finding is also in line with Social-Cognitive Domain Theory (e.g., Smetana \& Asquith, 1994; Smetana \& Daddis, 2002), which states that parents and adolescents generally agree that parents retain legitimate jurisdiction about morality issues throughout adolescence, whereas friendships are rather seen as private matters that are up to the adolescent to decide (Nucci, 1996), and therefore would fall under the adolescents' personal jurisdiction. In addition, the present investigation showed that adolescents reported more oppositional defiance to maternal friendship prohibitions, as compared to moral prohibitions. Such findings also seem to converge with Social-Cognitive Domain Theory. Indeed, as adolescents typically believe that friendship issues fall outside the boundaries of parents' authority, they might deem it more legitimate to defy to these prohibitions (Smetana, 2000, 2005). Surprisingly, however, no mean-level differences were found in adolescents' internalization of moral prohibitions, as opposed to friendship prohibitions. In other words, adolescents' endorsement of the maternal prohibitions did not so much depend on what is prohibited. 
Rather, in line with Self-Determination Theory (Ryan \& Deci, 2000), internalization especially seemed to depend on how the prohibitions are communicated, as outlined in greater detail below.

\section{Correlates of Degree of Prohibition and Communication Style}

The second aim of the current investigation was to examine the associations between mothers' degree and style of prohibition and the developmental outcomes, and to test whether the social domain moderated these associations. In general, the associations with adolescentreported degree of prohibition largely seemed to depend upon the domain. Specifically, whereas a higher adolescent-reported degree of prohibitions was related to stronger legitimacy perceptions and unrelated to oppositional defiance in the moral domain, the opposite pattern was true in the friendships domain, where it was unrelated to perceived legitimacy, and related to more oppositional defiance. In other words, these findings suggest that only forbidden friendships are perceived as attractive forbidden fruit (Keijsers et al., 2012); forbidden moral transgressions, by contrast, seem to be perceived as legitimately imposed expectations. It should be noted that associations between adolescent-perceived degree of prohibition and internalization were not significant, nor were the associations with the maternal reports of degree of prohibition. The latter finding suggests that effects of prohibitions are, at least to a certain extent, in "the eye of the beholder". Ultimately, adolescents' perceptions of the degree of prohibitions especially determine whether prohibitions are experienced as meddlesome and intrusive, or rather as legitimately imposed (Barber \& Harmon, 2002; Smetana \& Daddis, 2002).

The correlates of communication style were relatively more similar across domains and across informants. Consistent with Self-Determination Theory (Ryan \& Deci, 2000) and other socialization theories (e.g., Hoffman, 2000), an autonomy-supportive style was related to a more adaptive pattern of correlates (including higher scores for perceived legitimacy and 
internalization, and lower scores for oppositional defiance), whereas a controlling communicated style related negatively to the internalization of the maternal prohibitions. Such findings add to the literature by showing that, across social domains, an autonomysupportive communication style is an important lever to greater acceptance of the maternal prohibitions, whereas a controlling style, by contrast, seems ineffective and even counterproductive (Vansteenkiste et al., 2014).

Only one between-domain difference was obtained for maternal communication style, with a controlling communication style relating to oppositional defiance in the domain of friendships but not in the domain of morality. This finding suggests that a controlling style of prohibiting friendships in particular seems to foster psychological reactance (cf. Arim et al., 2010; Soenens et al., 2007; Van Petegem, Soenens, et al., 2015). This between-domain difference in the correlates of a controlling communication style suggests that its deleterious effects are especially pronounced with regards to issues that are assumed to fall under the adolescents' personal jurisdiction (i.e., friendships), as any parental interference in this domain is perceived as more intrusive (Arim et al., 2010; Kakihara \& Tilton-Weaver, 2009).

\section{Limitations and Directions for Future Research}

The current investigation has a number of limitations. First, given the cross-sectional design of the study, no inferences about causality or direction of effects can be made. Previous longitudinal research (e.g., Vansteenkiste et al., 2014) documented reciprocal associations, with parents' communication style not only predicting changes in adolescents' internalization and oppositional defiance but with adolescents' internalization and defiance in turn also predicting changes in parents' communication style. Thus, future research addressing between-domain similarities and differences in parental rules should ideally have a longitudinal design. A longitudinal design also allows for testing more advanced path models, 
such as a model including legitimacy perceptions as a mediator in the association between parental communication style and internalization and defiance (see Sunshine \& Tyler, 2003).

Second, although it is a notable strength that the current study explicitly compared two social domains through a within-person design, future research would do well also testing whether the uncovered dynamics operate similarly or differently in other social domains. For instance, previous research showed that the moral domain should be distinguished from the conventional domain, which involves agreed-on, arbitrary behaviors that structure social interactions in different settings, such as good manners (Smetana, 1995; Turiel, 1983). Similarly, previous studies also showed that the personal domain should be distinguished from the prudential domain, which also pertains to the understanding of the self, though it especially pertains to one's personal safety and well-being (e.g., Tisak \& Turiel, 1984; Smetana et al., 2005). Parents also are supposed to retain a certain degree of legitimate authority about these prudential issues (Smetana et al., 2005). Hence, future research could test whether our findings extend into different domains as well.

Third, future research also needs to test whether the current results, which involved the communication of “don'ts" (i.e., prohibitions), also apply to the communication of "do's" (i.e., requests to engage in specific behaviors). This is important because previous research has shown that the processes behind both types of parental interventions operate differently to some extent (e.g., Kochanska \& Aksan, 1995; Sheikh \& Janoff-Bulman, 2013).

Fourth, our sample was rather homogenous as it consisted of middle-class Belgian adolescents and their mothers. An interesting avenue for future research is to test to what degree the present findings generalize across cultures, as both Social-Cognitive Domain Theory and Self-Determination Theory make claims about universal dynamics. Specifically, Social-Cognitive Domain Theory states that individuals in all cultures develop and construct a personal domain, with a core set of issues that are seen as personal, even for young children 
(e.g., Assadi, Smetana, Shahmansouri, \& Mohammadi, 2011; Smetana, 2002). Hence, parental interference in this domain would relate to negative outcomes, regardless of the specific culture (e.g., Hasebe, Nucci, \& Nucci, 2004). Similarly, Self-Determination Theory claims that perceived controlling parenting would be deleterious for children and adolescents across cultures, as controlling parenting would frustrate adolescents' need for autonomy, which would be detrimental for everyone (e.g., Ahmad, Vansteenkiste \& Soenens, 2013; Chen et al., 2015; Soenens, Park, Vansteenkiste, \& Mouratidis, 2012). However, both theories also leave room for cultural variation (Soenens, Vansteenkiste, \& Van Petegem, 2015). For instance, according to Social-Domain Cognitive Theory, there may be variation between cultures (and between different developmental stages) in the specific boundaries that define the personal domain, and therefore also in what is considered to fall under one's personal jurisdiction (Smetana, 2002). Similarly, although perceived controlling parenting has been shown to be detrimental in many different cultures, there may be variation between cultures in the specific parenting practices that are perceived as autonomy-supportive or as controlling (Chen, Soenens, Vansteenkiste, Van Petegem, \& Beyers, 2016; Marbell \& Grolnick, 2013). Hence, an interesting future direction would be to examine where the cross-cultural similarities and differences lie.

Finally, we only considered mothers' prohibitions and their communication style. As noted previously (e.g., Lansford, Laird, Pettit, Bates, \& Dodge, 2014; Simons \& Conger, 2007), relatively little research has been done on father-adolescent dyads in the developmental field, as if the correlates of mothers' and fathers' parenting practices were identical. However, a growing body of literature documents important differences between mothers and fathers (e.g., Bornstein, 2015; Rogers et al., 2003). For instance, previous research found that adolescents, on average, reported more maternal than paternal psychological control (e.g., Lansford et al., 2014). It is also important to consider the gender 
composition of the family dyad, as some studies found that fathers are perceived to be more controlling by girls than by boys, whereas mothers are perceived to be more controlling by boys than by girls (e.g., Mantzouranis, Zimmermann, Biermann-Mahaim, \& Favez, 2012; Soenens et al., 2008). Hence, future studies also should consider the father-adolescent dyad when examining the correlates of parents' degree and style of prohibitions in different social domains.

\section{Conclusion}

A difficult question for parents is whether it is always wise to prohibit undesirable behaviors to their adolescent children. Many parents experience that prohibitions are sometimes risky and may turn out counterproductive. Drawing upon Social-Cognitive Domain Theory (Nucci, 1996; Smetana, 2006; Turiel, 1983) and Self-Determination Theory (Ryan \& Deci, 2000), the current study suggests that the effectiveness of parental prohibition depends both on what is prohibited and on how prohibitions are communicated. Specifically, it was found that friendship prohibitions generally are more difficult and challenging to communicate than moral prohibitions. However, prohibitions regarding both morality and friendships were found to be more effective (relating to stronger legitimacy perceptions, more internalization, and less oppositional defiance) when communicated in an autonomysupportive way rather than in a controlling way. 


\section{References}

Ahmad, I., Vansteenkiste, M., \& Soenens, B. (2013). The relations of Arab Jordanian adolescents' perceived maternal parenting to teacher-rated adjustment and problems: The intervening role of perceived need satisfaction. Developmental Psychology, 49, $177-183$.

Arim, R. G., Marshall, S. K., \& Shapka, J. D. (2010). A domain-specific approach to adolescent reporting of parental control. Journal of Adolescence, 33, 355-366.

Arnett, J. J. (1999). Adolescent storm and stress, reconsidered. American Psychologist, 54, 317-326.

Assadi, S. M., Smetana, J. G., Shahmansouri, N., \& Mohammadi, M. R. (2011). Iranian mothers' perceptions of parent-adolescent conflict: Effects of cultural values, parenting, and parental authority concepts. International Journal of Behavioral Development, 35, 424-431.

Barber, B. K. (1996). Parental psychological control: Revisiting a neglected construct. Child Development, 67, 3296-3319.

Barber, B. K., \& Harmon, E. L. (2002). Violating the self: Parental psychological control of children and adolescents. In B. K. Barber (Ed.), Intrusive parenting: How psychological control affects children and adolescents (pp. 15-52). Washington, DC: American Psychological Association.

Baudat, S., Zimmermann, G., Antonietti, J.-P., \& Van Petegem, S. (2016). The role of maternal communication style in adolescents' motivation to change alcohol use: A vignette-based study. Drugs: Education, Prevention, \& Policy. doi: 10.1080/09687637.2016.1192584.

Beal, C. R. (1994). Boys and girls: The development of gender roles. New York, NY: McGraw-Hill. 
Berk, L. E. (2014). Development across the lifespan (6 ${ }^{\text {th }}$ ed.). Boston, MA: Pearson.

Bornstein, M. H. (2015). Children's parents. In M. H. Bornstein \& T. Leventhal (Eds.), Ecological settings and processes in developmental systems. In R. M. Lerner (Editor-in-chief), Handbook of child psychology and developmental science (7th ed., Vol. 4). Hoboken, NJ: Wiley.

Buchanan, C. M., Eccles, J. S., Flanagan, C., Midgley, C., Feldlaufer, H., \& Harold, R. D. (1990). Parents' and teachers' beliefs about adolescents: Effects of sex and experience. Journal of Youth and Adolescence, 19, 363-394.

Chandler, C. L., \& Connell, J. P. (1987). Children's intrinsic, extrinsic, and internalized motivation: A study of children's reasons for liked and disliked activities. British Journal of Developmental Psychology, 5, 357-365.

Charness, G., Gneezy, U., \& Kuhn, M. A. (2012). Experimental methods: Between-subject and within-subject design. Journal of Economic Behavior and Organization, 81, 1-8.

Chen, B., Soenens, B., Vansteenkiste, M., Van Petegem, S., \& Beyers, W. (2016). Where do the cultural differences in dynamics of controlling parenting lie? Adolescents as active agents in the perception of and coping with parental behavior. Psychologica Belgica, 56, 169-192.

Chen, B., Vansteenkiste, M., Beyers, W., Boone, L., Deci, E. L., Duriez, B., Lens, W., Matos, L., Mouratidis, A., Ryan, R. M., Sheldon, K., Soenens, B., Van der Kaap-Deeder, J., Van Petegem, S. \& Verstuyf, J. (2015). Psychological need satisfaction, need frustration and need strength across four cultures. Motivation and Emotion, 39, 216236.

Crocker, J., \& Park, L. E. (2004). The costly pursuit of self-esteem. Psychological Bulletin, 130, 392-414.

Cumsille, P., Darling, N., Flaherty, B., \& Martinez, M. L. (2009). Heterogeneity and change 
in the patterning of adolescents' perceptions of the legitimacy of parental authority: A latent transition model. Child Development, 80, 418-432.

Darling, N., Cumsille, P., \& Martinez, M. (2008). Individual differences in adolescents' beliefs about the legitimacy of parental authority and their own obligation to obey: A longitudinal investigation. Child Development, 79, 1103-1118.

Deci, E. L., \& Ryan, R. M. (1985). Intrinsic motivation and self-determination in human behavior. New York: Plenum.

Deci, E. L., \& Ryan, R. M. (2000). The "what" and "why" of goal pursuits: Human needs and the self-determination of behavior. Psychological Inquiry, 11, 227-268.

De Los Reyes, A. (2013). Strategic objectives for improving understanding of informant discrepancies in developmental psychopathology research. Development and Psychopathology, 25, 669-682.

Fousiani, K., Van Petegem, S., Soenens, B., Vansteenkiste, M., \& Chen, B. (2014). Does parental autonomy support relate to more adolescent autonomy? An in-depth examination of a seemingly simple question. Journal of Adolescent Research, 29, 299330.

Galambos, N. L., Berenbaum, S. A., \& McHale, S. M. (2009). Gender development in adolescence. In R. M. Lerner \& L. Steinberg (Eds.), Handbook of adolescent psychology, Vol. 1: Individual bases of adolescent development (3rd ed., pp. 305-357). Hoboken, NJ: John Wiley.

Goossens, L., \& Luyckx, K. (2007). Belgium. In J. J. Arnett (Ed.), International encyclopedia of adolescence (pp. 64-76). New York: Routledge.

Grolnick, W. S. (2003). The psychology of parental control: How well-meant parenting backfires. Hillsdale, NJ: Lawrence Erlbaum Associates.

Grolnick, W. S., Deci, E. L., \& Ryan, R. M. (1997). Internalization within the family: The 
self-determination theory perspective. In J. E. Grusec, \& L. Kuczynski (Eds.), Parenting and children's internalization of values: A handbook of contemporary theory (pp. 135-161). New York: Wiley.

Grolnick, W. S., \& Pomerantz, E. M. (2009). Issues and challenges in studying parental control: Toward a new conceptualization. Child Development Perspectives, 3, 165-170.

Grolnick, W. S., Raftery-Helmer, J. N., Marbell, K. N., Flamm, E. S., Cardemil, E. V., \& Sanchez, M. (2014). Parental provision of structure: Implementation and correlates in three domains. Merrill-Palmer Quarterly, 60, 355-384.

Grusec, J. E., \& Goodnow, J. J. (1994). Impact of parental discipline methods on child's internalization of values: A reconceptualization of current points of view. Developmental Psychology, 30, 4-19.

Guttman, L. (1958). A new approach to factor analysis: The radex. In P. Lazerfeld (Ed.), Mathematical thinking in the social sciences (pp. 258-348). Glencoe, IL: Free Press.

Hasebe, Y., Nucci, L., \& Nucci, M. S. (2004). Parental control of the personal domain and adolescent symptoms of psychopathology: A cross-national study in the United States and Japan. Child Development, 75, 815-828.

Hoffman, M. L. (2000). Empathy and moral development: Implications for caring and justice. Cambridge University Press: New York.

Kakihara, F., \& Tilton-Weaver, L. (2009). Adolescents' interpretation of parental control: Differentiated by domains and types of control. Child Development, 80, 1722-1738.

Keijsers, L., Branje, S., Hawk, S. T., Schwartz, S. J., Frijns, T., Koot, H. M., van Lier, P., \& Meeus, W. (2012). Forbidden friends as forbidden fruit: parental supervision of friendships, contact with deviant peers, and adolescent delinquency. Child Development, 83, 651-666. 
Kochanska, G. (2002). Committed compliance, moral self, and internalization: A mediational model. Developmental Psychology, 38,339-351.

Kochanska, G., \& Aksan, N. (1995). Mother-child mutually positive affect, the quality of child compliance to requests and prohibitions, and maternal control as correlates of early internalization. Child Development, 66, 236-254.

Kochanska, G., Aksan, N., \& Koenig, A. L. (1995). A longitudinal study of the roots of preschoolers' conscience: Committed compliance and emerging internalization. Child Development, 66, 1752-1769.

Koestner, R., \& Losier, G. F. (1996). Distinguishing reactive versus reflective autonomy. Journal of Personality, 64, 465-494.

Kuczynski, L., \& Hildebrandt, N. (1997). Models of conformity and resistance in socialization theory. In J. E. Grusec \& L. Kuczynski (Eds.), Parenting and children's internalization of values: A handbook of contemporary theory (pp. 227-256). Hoboken, NJ: Wiley.

Kuczynski, L., \& Kochanska, G. (1990). Development of children's noncompliance strategies from toddlerhood to age 5. Developmental Psychology, 26, 398-408.

Kuhn, E. S., Phan, J. M., \& Laird, R. D. (2014). Compliance with parents' rules: Betweenperson and within-person predictions. Journal of Youth and Adolescence, 43, 245-256.

Kuhn, E. S., \& Laird, R. D. (2011). Individual differences in early adolescents' beliefs in the legitimacy of parental authority. Developmental Psychology, 47, 1353-1365.

Lagattuta, K. H., Nucci, L. \& Bosacki, S. L. (2010). Bridging theory of mind and the personal domain: Children's reasoning about resistance to parental control. Child Development, $81,616-635$.

Lansford, J. E., Laird, R. D., Pettit, G. S., Bates, J. E., \& Dodge, K. A. (2014). Mothers' and fathers' autonomy-relevant parenting: Longitudinal links with adolescents' 
externalizing and internalizing behavior. Journal of Youth and Adolescence, 43, 1877 1889.

Little, R. (1988). A test of missing completely at random for multivariate data with missing values. Journal of the American Statistical Association, 83, 1198-1202.

Maccoby, E. E. (2007). Historical overview of socialization research and theory. In J. E. Grusec, P. D. Hastings (Eds.), Handbook of socialization: Theory and research (pp. 13-41). New York: Guilford Press.

Mandara, J., \& Pikes, C. L. (2008). Guilt trips and love withdrawal: Does mothers' use of psychological control predict depressive symptoms among African American adolescents? Family Relations, 57, 602-612.

Mantzouranis, G., Zimmermann, G., Biermann Mahaim, E., \& Favez, N. (2012). A further examination of the distinction between dependency-oriented and achievementoriented parental psychological control: Psychometric properties of the DAPCS with French-speaking late adolescents. Journal of Child and Family Studies, 21, 726-733. Manly, B. F. J. (2006). Randomization, bootstrap and Monte Carlo methods in biology (3 ${ }^{\text {rd }}$ ed.). Boca Raton, FL: Taylor \& Francis.

Marbell, K. N., \& Grolnick, W. S. (2013). Correlates of parental control and autonomy support in an interdependent culture: A look at Ghana. Motivation \& Emotion, 37, 7992.

Mazerolle, L., Bennett, S., Davis, J., Sargeant, E., \& Manning, M. (2013). Procedural justice and police legitimacy: A systematic review of the research evidence. Journal of Experimental Criminology, 9, 245-274.

Morris, A. S., Steinberg, L., Sessa, F. M., Avenevoli, S., Silk, J. S., \& Essex, M. J. (2002). Measuring children's perceptions of psychological control: Developmental and conceptual considerations. In B. K. Barber (Ed.), Intrusive parenting: How 
psychological control affects children and adolescents (pp. 125-159). Washington, DC: American Psychological Association.

Neyrinck, B., Vansteenkiste, M., Lens, W., Duriez, B., \& Hutsebaut, D. (2006). Cognitive, behavioral and affective correlates of internalization of regulations for religious activities. Motivation and Emotion, 30, 323-334.

Nucci, L. (1981). Conceptions of personal issues: A domain distinct from moral or societal concepts. Child Development, 52, 114-121.

Nucci, L. (1996). Morality and personal freedom. In E. S. Reed, E. Turiel, \& T. Brown (Eds.), Knowledge and values (pp. 41-60). Mahwah, NJ: Lawrence Erlbaum.

Nucci, L. (2001). Education in the moral domain. Cambridge: Cambridge University Press.

Mounts, N. S. (2001). Young adolescents' perceptions of parental management of peer relationships. Journal of Early Adolescence, 21, 92-122.

Padilla-Walker, L. M., \& Carlo, G. (2006). Adolescent perceptions of appropriate parental reactions in moral and conventional social domains. Social Development, 15, 480-500.

Parkin, C. M., \& Kuczynski, L. (2012). Adolescent perspectives on rules and resistance within the parent-child relationship. Journal of Adolescent Research, 27, 632-658.

Pavey, L., \& Sparks, P. (2009). Reactance, autonomy and paths to persuasion: Examining perceptions of threats to freedom and informational value. Motivation and Emotion, $33,277-290$.

Pelletier, L. G., Fortier, M. S., Vallerand, R. J., \& Briere, N. M. (2001). Associations among perceived autonomy support, forms of self-regulation, and persistence: A prospective study. Motivation \& Emotion, 25, 279-306.

R Development Core Team. (2014). R: A language and environment for statistical computing. Vienna, Austria: R Foundation for Statistical Computing. 
Rogers, K. N., Buchanan, C. M., \& Winchell, M. E. (2003). Psychological control during early adolescence: Links to adjustment in differing parent/adolescent dyads. The Journal of Early Adolescence, 23, 349-383.

Rote, W. M., \& Smetana, Y. G. (2016). Patterns and predictors of mother-adolescent discrepancies across family constructs. Journal of Youth and Adolescence. Doi: 10.1007/s10964-016-0515-1.

Ryan, R. M., \& Connell, J. P. (1989). Perceived locus of causality and internalization: Examining reasons for acting in two domains. Journal of Personality and Social Psychology, 57, 749-761.

Ryan, R. M., \& Deci, E. L. (2000). Self-determination theory and the facilitation of intrinsic motivation, social development, and well-being. American Psychologist, 55, 68-78.

Schafer, J. L. (1997). Analysis of incomplete multivariate data. London: Chapman \& Hall.

Sheikh, S., \& Janoff-Bulman, R. (2013). Paradoxical consequences of prohibitions. Journal of Personality and Social Psychology, 105, 301-315.

Simons, L. G., \& Conger, R. D. (2007). Linking mother-father differences in parenting to a typology of family parenting styles and adolescent outcomes. Journal of Family Issues, $28,212-241$.

Skinner, E. A., \& Edge, K. (2002). Self-determination, coping and development. In E. L. Deci \& R. M. Ryan (Eds.), Self-determination theory: Extensions and applications (pp. 297-337). Rochester, NY: University of Rochester Press.

Smetana, J. G. (1989). Adolescents' and parents' reasoning about actual family conflict. Child Development, 60, 1052-1067.

Smetana, J. G. (1999). The role of parents in moral development: A social domain analysis. Journal of Moral Education, 28, 311-321. 
Smetana, J. G. (2000). Middle-class African American adolescents' and parents' conceptions of parental authority and parenting practices: A longitudinal investigation. Child Development, 71, 1672-1686.

Smetana, J. G. (2002). Culture, autonomy, and personal jurisdiction in adolescent-parent relationships. In H. W. Reese \& R. Kail (Eds.), Advances in Child Development and Behavior, Vol. 29 (pp. 51-87). New York, NY: Academic Press.

Smetana, J. G. (2005). Adolescent-parent conflict: Resistance and subversion as developmental process. In L. Nucci (Ed.), Conflict, contradiction, and contrarian elements in moral development and education (pp.69-91). Mahwah, NJ: Lawrence Erlbaum.

Smetana, J. G. (2006). Social-cognitive domain theory: Consistencies and variations in children's moral and social judgments. In M. Killen \& J. Smetana (Eds.), Handbook of moral development (pp. 119-153). Mahwah, NJ: Lawrence Erblaum.

Smetana, J. G., \& Asquith, P. (1994). Adolescnts' and parents' conceptions of parental authority and personal autonomy. Child Development, 65,1147-1162.

Smetana, J. G., Crean, H. F., \& Campione-Barr, N. (2005). Adolescents' and parents' changing conceptions of parental authority. New Directions for Child and Adolescent Development, 108, 3146.

Smetana, J. G., \& Daddis, C. (2002). Domain-specific antecedents of parental psychological control and monitoring: The role of parenting beliefs and practices. Child Development, 73, 563-580.

Smetana, J. G., Villalobos, M., Rogge, R. D., \& Tasopoulos-Chan, M. (2010). Keeping secrets from parents: Daily variations among poor, urban adolescents. Journal of Adolescence, 33, 321-331. 
Soenens, B., Luyckx, K., Vansteenkiste, M., Duriez, B., \& Goossens, L. (2008). Clarifying the link between parental psychological control and adolescents' depressive symptoms. Merrill-Palmer Quaterly, 54, 411-444.

Soenens, B., Park, S. Y., Vansteenkiste, M., \& Mouratidis, A. (2012). Perceived parental psychological control and adolescent depressive experiences: A cross-cultural study with Belgian and South-Korean adolescents. Journal of Adolescence, 35, 261-272.

Soenens, B., \& Vansteenkiste, M. (2010). A theoretical upgrade of the concept of parental psychological control: Proposing new insights on the basis of self-determination theory. Developmental Review, 30, 74-99.

Soenens, B., Vansteenkiste, M., Lens, W., Luyckx, K., Goossens, L., Beyers, W., \& Ryan, R. M. (2007). Conceptualizing parental autonomy support: Adolescent perceptions of promotion of independence versus promotion of volitional functioning. Developmental Psychology, 43, 633-646.

Soenens, B., Vansteenkiste, M., \& Niemiec, C. P. (2009). Should parental prohibition of adolescents' peer relationships be prohibited? Personal Relationships, 16, 507-530.

Soenens, B. Vansteenkiste, M., Smits, I., Lowet, K., \& Goossens, L. (2007). The role of intrusive parenting in the relationship between peer management strategies and peer affiliation. Journal of Applied Developmental Psychology, 28, 239-249.

Soenens, B., Vansteenkiste, M., \& Van Petegem, S. (2015). Let's not throw out the baby with the bathwater: Applying the principle of universalism without uniformity to autonomy-supportive and controlling parenting. Child Development Perspectives, 9, 44-49.

Steinberg, L., \& Morris, A. S. (2001). Adolescent development. Annual Review of Psychology, 52, 83-110.

Sunshine, J., \&Tyler, T. R. (2003). The role of procedural justice and legitimacy in shaping 
public support for policing. Law \& Society Review, 37, 513-547.

Tisak, M. S. (1986). Children's conceptions of parental authority. Child Development, 57, $166-176$.

Tisak, M. S., \& Turiel, E. (1984). Children's conceptions of moral and prudential rules. Child Development, 55, 1030-1039.

Trinkner, R., Cohn, E. S., Rebellon, C. J., \& Van Gundy, K. (2012). Don't trust anyone over 30: Parental legitimacy as a mediator between parenting styles and changes in delinquent behavior over time. Journal of Adolescence, 35, 119-132.

Turiel, E. (1983). The development of social knowledge: Morality and convention. Cambridge: Cambridge University Press.

Tyler, T. R. (2006). Psychological perspectives on legitimacy and legitimation. Annual Review of Psychology, 57, 375-400.

Vallerand, R. J., Fortier, M. S., \& Guay, F. (1997). Self-determination and persistence in a real-life setting: Toward a motivational model of high school dropout. Journal of Personality and Social Psychology, 72, 1161-1176.

Van der Kaap-Deeder, J., Wouters, S., Verschueren, K., Briers, V., Deeren, B., \& Vansteenkiste, M. (2016). The pursuit of self-esteem and its motivational implications. Psychologica Belgica, 56, 143-168.

Van Petegem, S., Soenens, B., Vansteenkiste, M., \& Beyers, W. (2015). Rebels with a cause? Adolescent defiance considered from the perspective of reactance theory and selfdetermination theory. Child Development, 86, 903-918.

Van Petegem, S., Vansteenkiste, M., Soenens, B., Beyers, W., \& Aelterman, N. (2015). Examining the longitudinal association between oppositional defiance and autonomy in adolescence. Developmental Psychology, 51, 67-74.

Vansteenkiste, M., Soenens, B., Van Petegem, S., \& Duriez, B. (2014). Longitudinal 
associations between adolescent perceived style of parental prohibition and oppositional defiance and internalization. Developmental Psychology, 50, 229-236.

West, B. T., Welch, K. B., \& Galecki, A. T. (2014). Linear mixed models: A practical guide using statistical software (2nd ed.). Boca Raton, FL: Chapman \& Hall/CRC. 


\section{Tables}

Table 1

Correlations among Mothers' Degree and Style of Prohibition and Adolescent Developmental Outcomes in the Friendship domain (Below Diagonal) and the Moral Domain (Above Diagonal)

\begin{tabular}{lccccccccc}
\hline & 1. & 2. & 3. & 4. & 5. & 6. & 7. & 8. & 9. \\
\hline 1. Degree of Prohibition - AR & - & $.21^{* *}$ & $.22^{* *}$ & $.15^{*}$ & $.26^{* * *}$ & -.03 & $.41^{* * *}$ & .04 & -.09 \\
2. Autonomy-Supportive Style - AR & $-.19^{* *}$ & - & $-.29 * * *$ & -.11 & $.27 * * *$ & -.10 & $.45^{* * *}$ & $.47^{* * *}$ & $-.35^{* * *}$ \\
3. Controlling Style - AR & $.48^{* * *}$ & $-.38^{* * *}$ & - & .00 & -.09 & $.33^{* * *}$ & -.11 & $-.37^{* * *}$ & $.22^{* *}$ \\
4. Degree of Prohibition - MR & $.44^{* * *}$ & $-.25^{* * *}$ & $.31^{* * *}$ & - & $.27 * * *$ & $.17^{*}$ & .01 & .04 & .05 \\
5. Autonomy-Supportive Style - MR & -.07 & $.30^{* * *}$ & $-.21^{* *}$ & -.01 & - & -.02 & $.30^{* * *}$ & $.22^{* *}$ & $-.26^{* * *}$ \\
6. Controlling Style - MR & $.38^{* * *}$ & $-.15^{*}$ & $.38^{* * *}$ & $.41 * * *$ & -.10 & - & $-.16^{*}$ & $-.22^{* *}$ & $.20^{* *}$ \\
7. Legitimacy & -.12 & $.31^{* * *}$ & $-.20^{* *}$ & .03 & .12 & -.14 & - & $.44^{* * *}$ & $-.42^{* * *}$ \\
8. Internalization & $-.25^{* * *}$ & $.35^{* * *}$ & $-.42^{* * *}$ & -.07 & $.18^{*}$ & -.12 & $.29^{* * *}$ & - & $-.52^{* * *}$ \\
9. Oppositional Defiance & $.42^{* * *}$ & $-.37^{* * *}$ & $.48^{* * *}$ & $.22^{* *}$ & $-.18^{*}$ & $.20^{* *}$ & $-.36^{* * *}$ & $-.55^{* * *}$ & - \\
\hline
\end{tabular}

Note. $\mathrm{AR}=$ adolescent report, $\mathrm{MR}=$ mother report.

$* p<.05, * * p<.01, * * * p<.001$. 
Table 2

Means and Standard Deviations for All Variables

\begin{tabular}{lcccc}
\hline & \multicolumn{2}{c}{ Friendship Domain } & \multicolumn{2}{c}{ Moral Domain } \\
& $M$ & $S D$ & $M$ & $S D$ \\
\cline { 2 - 5 } & & & & \\
Prohibition - Adolescent Report & 1.86 & 0.75 & 3.91 & 0.92 \\
$\quad$ Degree of Prohibition & 3.94 & 0.97 & 3.81 & 0.98 \\
Autonomy-Supportive Style & 1.52 & 0.60 & 2.09 & 0.82 \\
Controlling Style & & & & \\
Prohibition - Mother Report & 2.15 & 0.91 & 4.17 & 1.02 \\
Degree of Prohibition & 4.32 & 0.78 & 4.46 & 0.67 \\
Autonomy-Supportive Style & 1.56 & 0.69 & 2.29 & 0.95 \\
Controlling Style & & & & \\
Developmental Outcomes & 2.98 & 1.21 & 4.17 & 0.80 \\
$\quad$ Legitimacy & 3.09 & 2.95 & 3.15 & 2.89 \\
Internalization & 1.81 & 0.90 & 1.56 & 0.72 \\
Oppositional Defiance & & & & \\
\hline
\end{tabular}


Table 3

Summary of Linear Mixed Models Examining the Relation Between Parents' Degree and Style of Prohibition and Adolescent Developmental Outcomes

\begin{tabular}{|c|c|c|c|c|c|c|}
\hline & \multicolumn{2}{|c|}{ Legitimacy } & \multicolumn{2}{|c|}{ Internalization } & \multicolumn{2}{|c|}{ Oppositional Defiance } \\
\hline & AR & MR & AR & MR & AR & MR \\
\hline \multicolumn{7}{|l|}{ Fixed-Effect Parameters } \\
\hline Gender & .00 & -.04 & -.02 & -.08 & -.08 & -.04 \\
\hline Age & -.01 & -.02 & $.14^{*}$ & .11 & $-.14 *$ & $-.12 *$ \\
\hline Domain & -.03 & -.27 & .35 & -.07 & -.09 & .15 \\
\hline Degree of Prohibition & $.33 * * *$ & -.03 & .05 & .06 & .02 & .10 \\
\hline Autonomy-Supportive Style & $.25^{* * *}$ & $.21 * *$ & $.26^{* * *}$ & .08 & $-.18 * * *$ & $-.17 * *$ \\
\hline Controlling Style & -.06 & -.10 & $-.19 * * *$ & $-.13 *$ & .08 & .10 \\
\hline Domain $\times$ Degree of Prohibition & $-.31 * * *$ & .18 & -.11 & -.02 & $.25^{*}$ & .10 \\
\hline Domain $\times$ Autonomy-Supportive Style & .06 & -.33 & -.27 & .02 & -.08 & .02 \\
\hline Domain $\times$ Controlling Style & -.03 & -.13 & -.07 & .08 & $.21 *$ & .00 \\
\hline \multicolumn{7}{|l|}{ Random Parameters } \\
\hline Intercept variance & 0.166 & 0.242 & 4.297 & 5.962 & 0.279 & 0.396 \\
\hline Residual variance & 0.727 & 0.762 & 2.266 & 2.123 & 0.230 & 0.209 \\
\hline \multicolumn{7}{|l|}{ Model Fit Criteria } \\
\hline -2 REML log-likelihood & 1051.3 & 1091.9 & 1730.1 & 1767.8 & 767.6 & 795.9 \\
\hline AIC & 1108.6 & 1148.5 & 1770.2 & 1807.3 & 832.1 & 860.0 \\
\hline BIC & 1156.3 & 1196.1 & 1817.9 & 1855.0 & 879.7 & 907.7 \\
\hline
\end{tabular}

Note. $\mathrm{AR}=$ adolescent report, $\mathrm{MR}=$ mother report. Standardized partial regression coefficients are presented.

$* p<.05, * * p<.01, * * * p<.001$. 


\section{Figures}

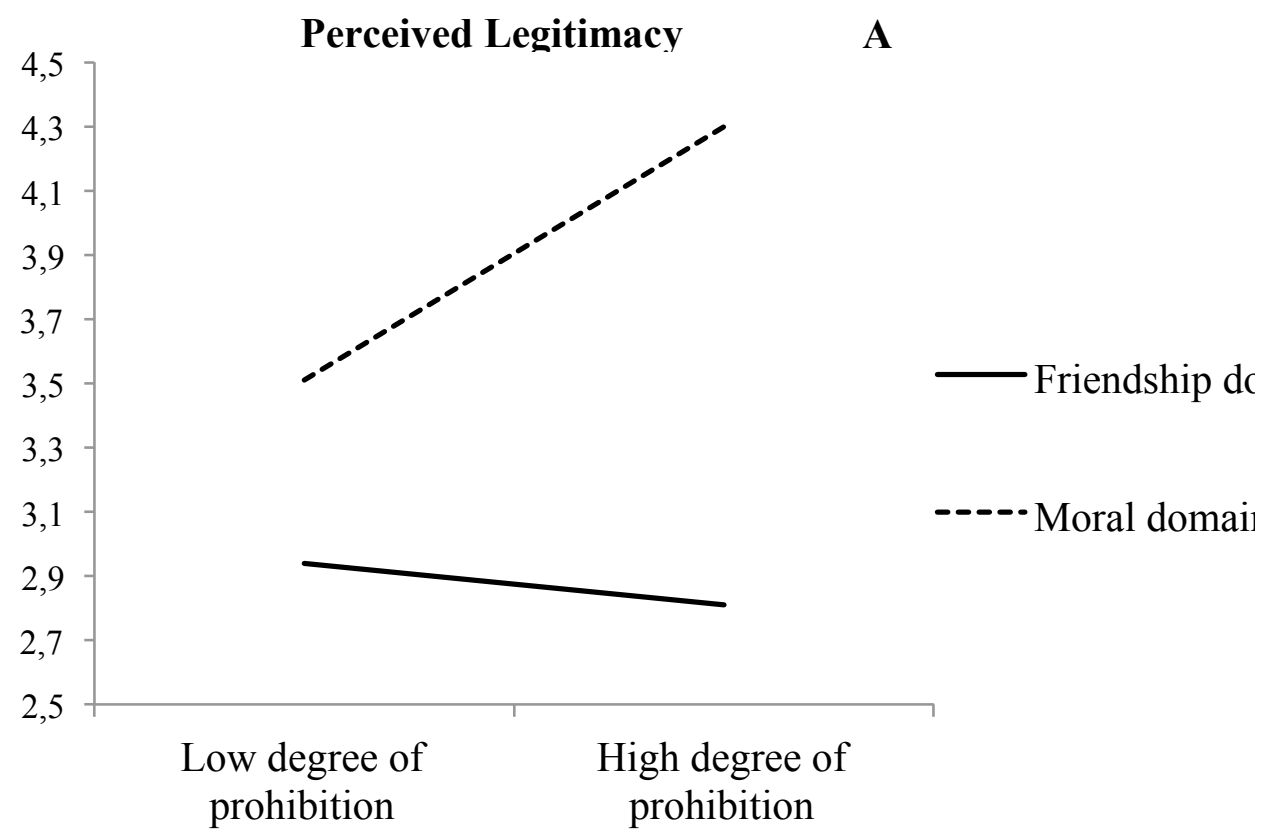

Oppositional Defiance

B

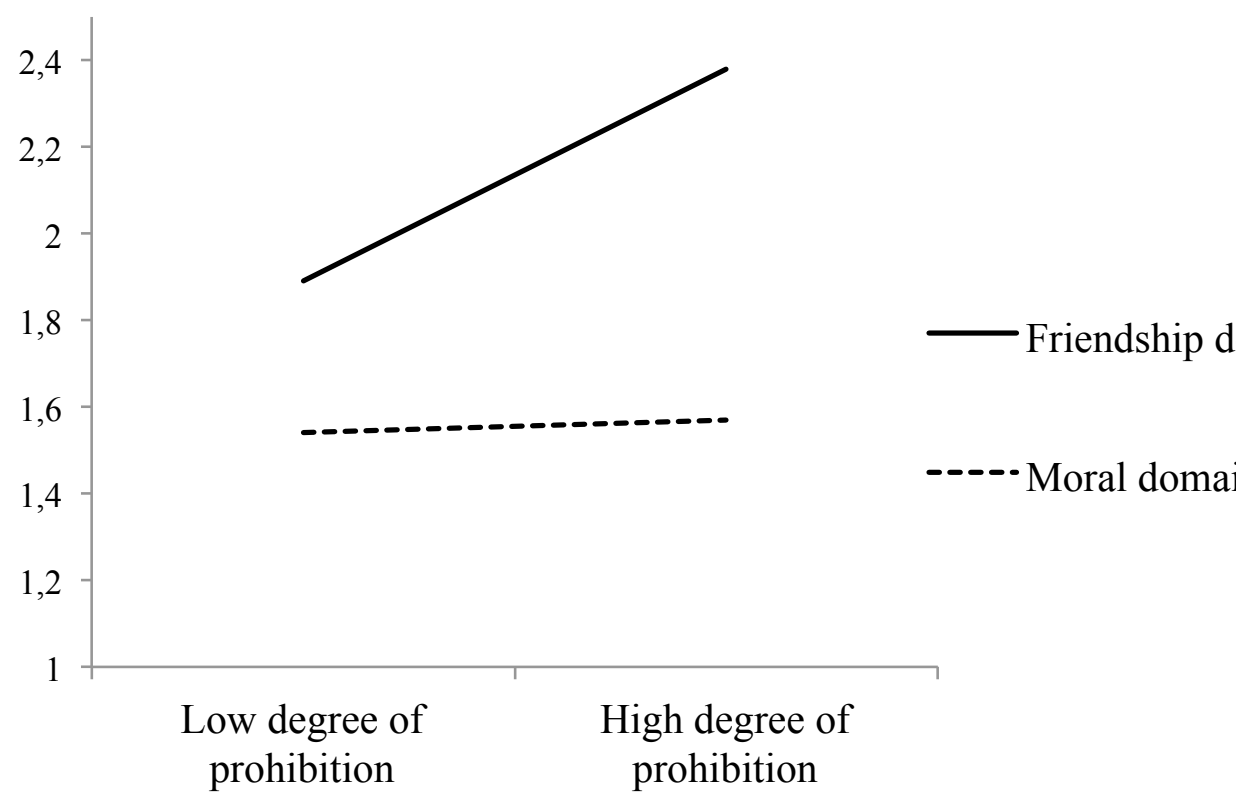




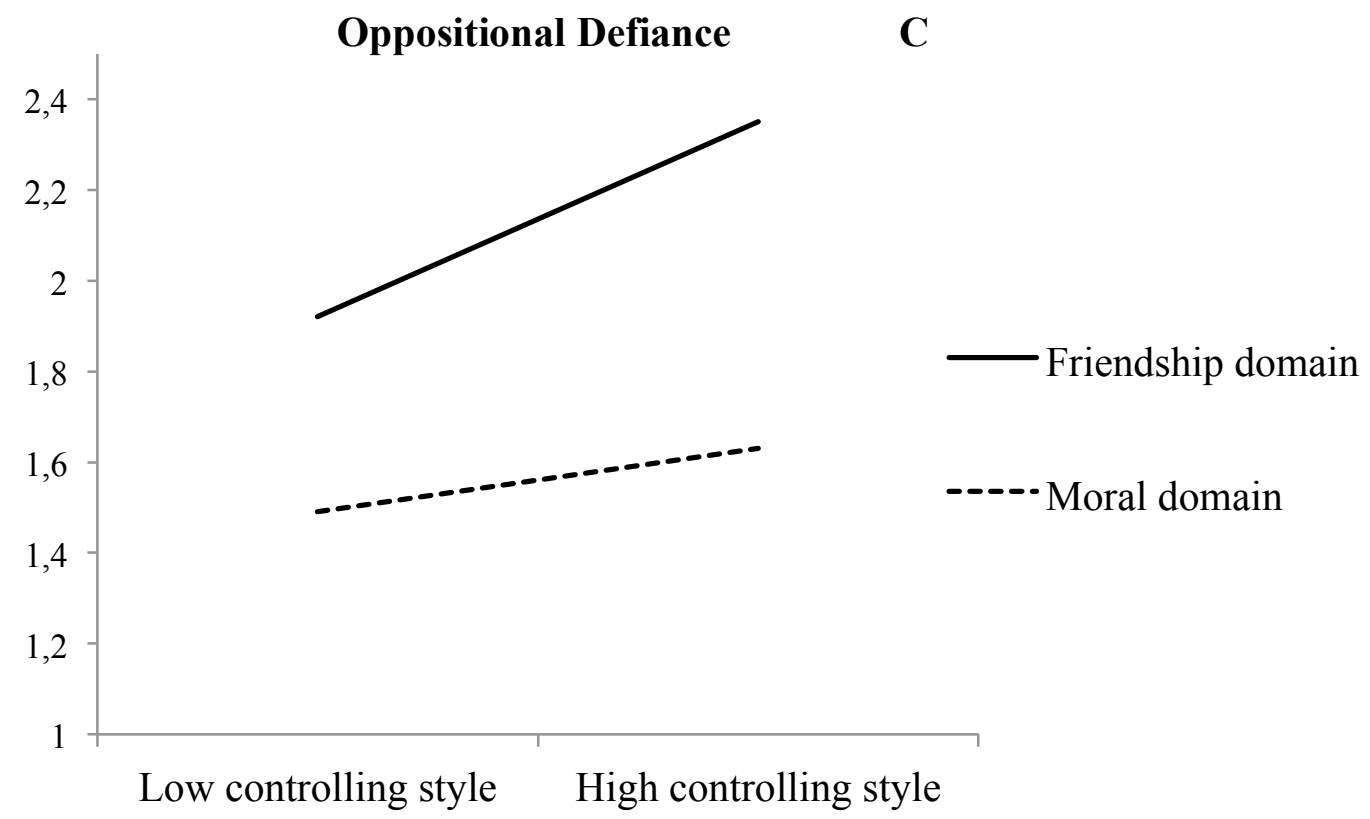

Figure 1. The moderating role of social domain in the association between degree of prohibition and perceived legitimacy (A), between degree of prohibition and oppositional defiance (B), and between controlling communication style and oppositional defiance (C) 